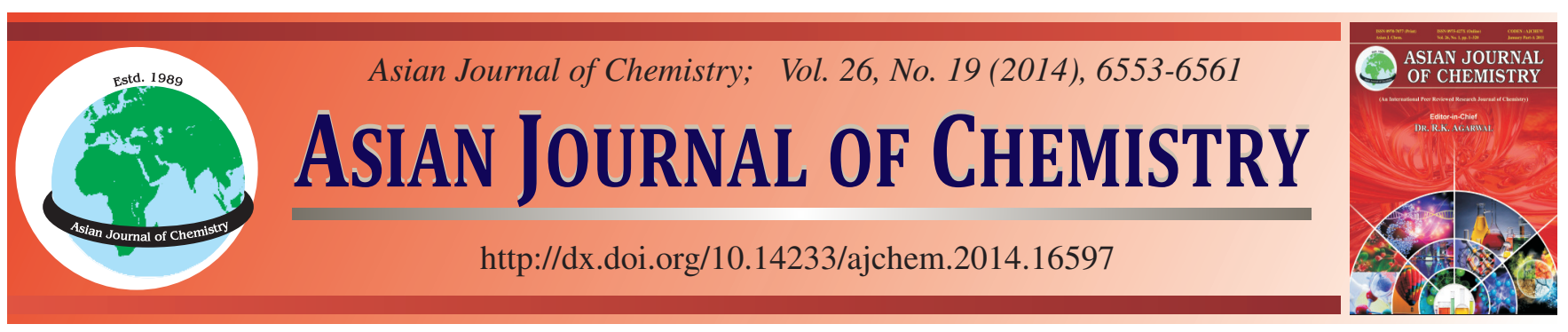

\title{
Adsorption Efficiency of Crystal Violet Onto Green House Gas Emitting Agro-Waste Obtained from Areca Husk Carbon
}

\section{A. BASKer ${ }^{1, *}$, P.S. Syed ShabUdeEn ${ }^{2}$ and A.P. SheKhar ${ }^{3}$}

\author{
${ }^{1}$ Department of Chemistry, Kalaignar Karunanidhi Institute of Technology, Coimbatore-641 402, India \\ ${ }^{2}$ Department of Chemistry, Kumaraguru College of Technology, Coimbatore-641 049, India \\ ${ }^{3}$ Department of Chemistry, Chikkanna Goverment Arts College, Tirupur-641 602, India \\ *Corresponding author: E-mail: baskerchemistry@gmail.com
}

\begin{abstract}
An activated carbon produced from agricultural waste was utilized for the adsorption studies of crystal violet from its aqueous solutions. Batch experiments were carried out for the adsorption of dye molecules onto areca husk carbon at room temperature. The factors affecting the rate processes involved in the removal of dye for particle size, adsorbent dosage, initial dye concentration, contact time, $\mathrm{pH}$ and temperature have been studied. Pseudo-first order, pseudo-second order kinetics and intra particle diffusion models were attempted to examine the feasibility of the experimental data based upon different initial concentrations. The observed kinetics studies show that the adsorption followed pseudo-first order reaction. The high correlation coefficient of intra particle diffusion model proves the pore diffusion plays an effective role for the adsorption of crystal violet onto areca husk carbon. This adsorption isotherm data was in agreement with the Langmuir, Freundlich and Temkin adsorption isotherm models. Thermodynamic parameters have also been evaluated. The structural and morphological of activated carbon were characterized by FTIR and SEM studies respectively. Main and interaction effects were analyzed by analysis of variance (ANOVA), F-test and p-values to define most important process variables affecting the dye adsorption.
\end{abstract}

Keywords: Areca husk carbon, Crystal violet, Kinetics, Isotherm, Thermodynamics, ANOVA study.

\section{INTRODUCTION}

Dyes are normally used in industries such as textiles, printing, paper, pharmaceutical, Kraft bleaching, food technology, hair coloring, plastics, cosmetics, etc. During these processes, they persist for long distances in flowing water, retards photosynthetic activity, inhibit the growth of aquatic biota by blocking out the sunlight and utilizing dissolved oxygen and also decrease the recreation value of stream. One of the most effective treatment technologies prevailed to remove dyes from these waste water bodies are by using activated carbon and the adsorption process have been proved to be highly efficient for the removal of dye from waste water. However its use is limited owing to the high cost of activated carbon and the problem of regeneration. This fact has led to the search for low cost renewable, locally available material for use of activated carbon such as pinus bark powder ${ }^{1}$, citrus waste biomass ${ }^{2}$, bagasse ${ }^{3}$, barley husk and rice husk ${ }^{4}$, modified rice husk ${ }^{5}$, male flowers of coconut tree ${ }^{6}$, polyacrylic acid bound magnetic nanoparticles ${ }^{7}$, coconut coir and banana peel ${ }^{8}$, wheat straw leaves ${ }^{9}$, saw dust ${ }^{10,11}$. In the present work we have attempted the use of areca husk carbon in the adsorption of crystal violet dye (Fig. 1). A low cost effective process and efficient adsorption of dye pollutant have been noticed in the present work.<smiles>CCN(C)CCN(C)C</smiles>

Fig .1. Chemical structure of crystal violet

The main aim of this study was to investigate the potentiality of using areca husk carbon as an adsorbent for the adsorption of crystal violet. The effects of particle size, adsorbent dosage, initial dye concentration, contact time, $\mathrm{pH}$ and temperature on crystal violet adsorption were studied. The kinetic parameters such as pseudo first order, pseudo second order and intra particle diffusion model were also calculated to determine the rate constants. The equilibrium experimental studies were attempted to Langmuir, Freundlich and Temkin 
equation. Thermodynamic activation parameters such as free energy change $\left(\Delta \mathrm{G}^{0}\right)$, enthalpy $\left(\Delta \mathrm{H}^{0}\right)$ and entropy $\left(\Delta \mathrm{S}^{0}\right)$ were also calculated. Main and interaction effects were analyzed by using ANOVA model.

\section{EXPERIMENTAL}

Preparation of activated carbon adsorbent and stock solution: Areca husk was cut into small pieces, dried in sunlight, then $75^{\circ} \mathrm{C}$ for $24 \mathrm{~h}$ in hot air oven. The dried material is digested with sulphuric acid in the ratio 1:1 and kept at room temperature overnight. It was washed with double distilled water to remove the excess acid and kept in hot air oven at $85^{\circ} \mathrm{C}$ for $12 \mathrm{~h}$. Then it was taken in an iron vessel in muffle furnace and the temperature was gradually raised to $550{ }^{\circ} \mathrm{C}$ for $1 \mathrm{~h}$, ground well by using ball mill and then sieved into particle size of 100,150 and 250 BSS mesh numbers and kept in air tight containers for further use. The preparation of stock solution of crystal violet dye for 1000 ppm by using double distilled water. The stock solutions were diluted with known initial concentrations say 10, 20, 40, 60, 80 and $100 \mathrm{mg} \mathrm{L}^{-1}$ in accurate proportions. These dye solutions were taken for adsorption studies with areca husk carbon.

Analysis of crystal violet: The concentration of crystal violet in the supernatant solution after and before adsorption was determined using a double beam UV spectrophotometer (Shimadzu, Japan) at $559 \mathrm{~nm}$. It was found that the supernatant from the activated carbon did not exhibit any absorbance at this wavelength and also that the calibration curve was very reproducible and linear over the concentration range used in this work.

Batch equilibrium studies: Crystal violet solutions were prepared with distilled water. Batch experiments were carried in a glass beaker by shaking a fixed mass areca husk carbon $\left(100 \mathrm{mg}\right.$ ) with $100 \mathrm{~mL}$ diluted solution (20-100 $\left.\mathrm{mg} \mathrm{L}^{-1}\right)$. After agitation the solution centrifuged. Then the dye concentration in the supernatant solution was analyzed using a spectrophotometer by monitoring the absorbance changes at a wavelength of maximum absorbance $(559 \mathrm{~nm})$ in these sorption experiments, the solution was used without adjusting $\mathrm{pH}$. Each experiment was carried out duplicate and the average results are presented. Calibration curves were obtained with standard crystal violet solution using distilled water as a blank. Mass capacity of adsorption $\mathrm{q}_{\mathrm{e}}$ is calculated from the difference between the initial and final concentration of crystal violet.

$$
\mathrm{q}_{\mathrm{e}}=\frac{\left(\mathrm{C}_{\mathrm{o}}-\mathrm{C}_{\mathrm{e}}\right)}{\mathrm{W}} \mathrm{V}
$$

where $\mathrm{C}_{0}$ and $\mathrm{C}_{\mathrm{e}}\left(\mathrm{mg} \mathrm{L}^{-1}\right)$ are the liquid-phase concentrations of dye at initial and equilibrium respectively. $\mathrm{V}$ is the volume of the solution (1) and $\mathrm{W}$ is the mass of dry adsorbent used ( $\mathrm{g}$ ).

Batch kinetic studies: The procedures of kinetic experiments were basically identical to those of equilibrium tests. The aqueous samples were taken at preset time intervals and the concentrations of dye were similarly measured. The amount of adsorption ${ }^{12}$ at time $\mathrm{t}_{\mathrm{t}}\left(\mathrm{mg} \mathrm{g}^{-1}\right)$ was calculated by:

$$
\mathrm{q}_{\mathrm{t}}=\frac{\left(\mathrm{C}_{\mathrm{o}}-\mathrm{C}_{\mathrm{t}}\right)}{\mathrm{W}} \mathrm{V}
$$

where $\mathrm{C}_{0}$ and $\mathrm{C}_{\mathrm{t}}\left(\mathrm{mg} \mathrm{L}^{-1}\right)$ are the liquid-phase concentrations of dye at initial and any time t, respectively. $\mathrm{V}$ is the volume of the solution (l) and $\mathrm{W}$ is the mass of dry adsorbent used ( $\mathrm{g}$ ).

\section{RESULTS AND DISCUSSION}

The FT-IR spectrum of crystal violet on areca husk carbon before and after adsorption was detected in the range of 4000 to $400 \mathrm{~cm}^{-1}$ was presented in Figs. 2 and 3 respectively. The band observed at $3425.58 \mathrm{~cm}^{-1}$ was assigned to a $\mathrm{v}(\mathrm{O}-\mathrm{H})$ stretching vibration. The absorption band at 2854.65 and $2924.09 \mathrm{~cm}^{-1}$ can be attributed to the stretching vibrations of $v(\mathrm{C}-\mathrm{H})$ bonds in alkane and alkyl groups where carbon is bonded with hydrogen bonds. Adsorption bands at 2337.72 and $2376.30 \mathrm{~cm}^{-1}$ were corresponds to $\mathrm{v}(\mathrm{N}-\mathrm{H})$ stretching. The band at 1573.91 and $1581.63 \mathrm{~cm}^{-1}$ shows the asymmetric $v$ (-COO-) stretching. The band at 1450.47 and $1458.18 \mathrm{~cm}^{-1}$ may be attributed to the aromatic $\mathrm{v}(\mathrm{C}=\mathrm{C})$ stretching vibration. At 1111 and $1095.57 \mathrm{~cm}^{-1}$, the band is highly intense $v(\mathrm{C}-\mathrm{O})$ and is related to the $\mathrm{v}(\mathrm{C}-\mathrm{O})$ stretching vibration of the bonds in ester, ether, or phenol groups. The band corresponding to $802.39 \mathrm{~cm}^{-1}$ in the fingerprint area indicates a mono substituted aromatic structure. The weak absorption band at $678.94 \mathrm{~cm}^{-1}$ corresponds to the $\mathrm{v}(\mathrm{O}-\mathrm{H})$ vibration in the benzene ring. The bands at 462.92 and $594.08 \mathrm{~cm}^{-1}$ which were associated with the in-plane and out-of-plane aromatic ring deformation vibrations common that is quite common for activated carbon.

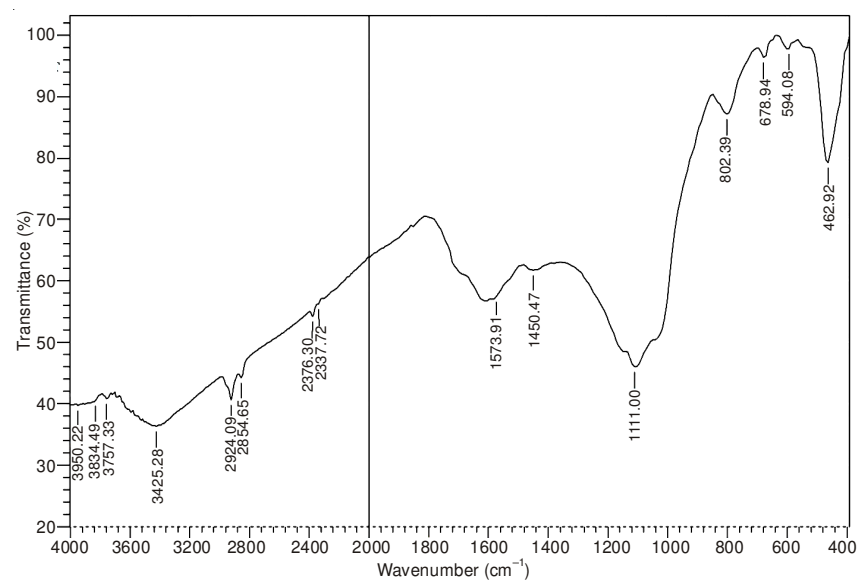

Fig. 2. FTIR spectra of fresh areca husk carbon

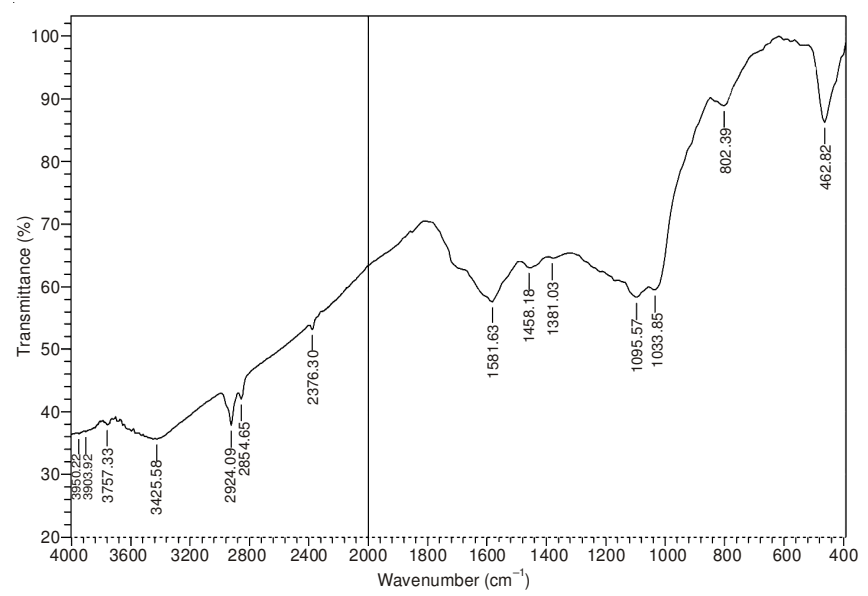

Fig. 3. FTIR spectra of crystal violet loaded areca husk carbon 
The peak at $1381.03 \mathrm{~cm}^{-1}$ indicates the existence of phenolic structure. Some of the peak was disappear due to the absorption of crystal violet on areca husk carbon.

SEM images: Surface morphology of adsorbents was analyzed by scanning electron microscopy which showed a clear view of the grains of the materials used as adsorbent in this study. Typical SEM photographs are shown in Fig. 4. It reveals that the areca husk carbon has a rough and uneven surface with more porous and caves like structure. The SEM Fig. 5 shows the morphology of the loaded adsorbent, the surface of the adsorbent due to adsorption of the crystal violet dye molecules, presumably leading to formation of a monolayer of the dye molecule over the adsorbent surface is evident from the formation of white layer and it is supported with FTIR spectra as shown in Fig. 3.

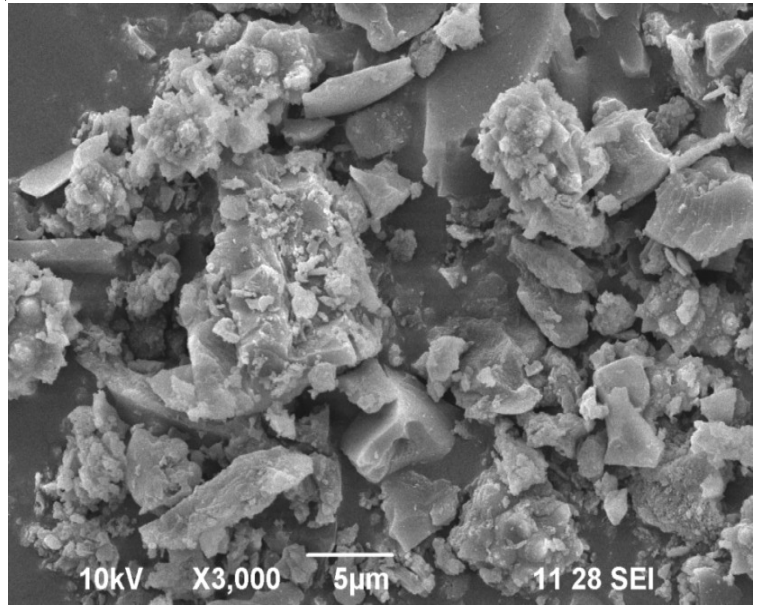

Fig. 4. SEM image of fresh areca husk carbon

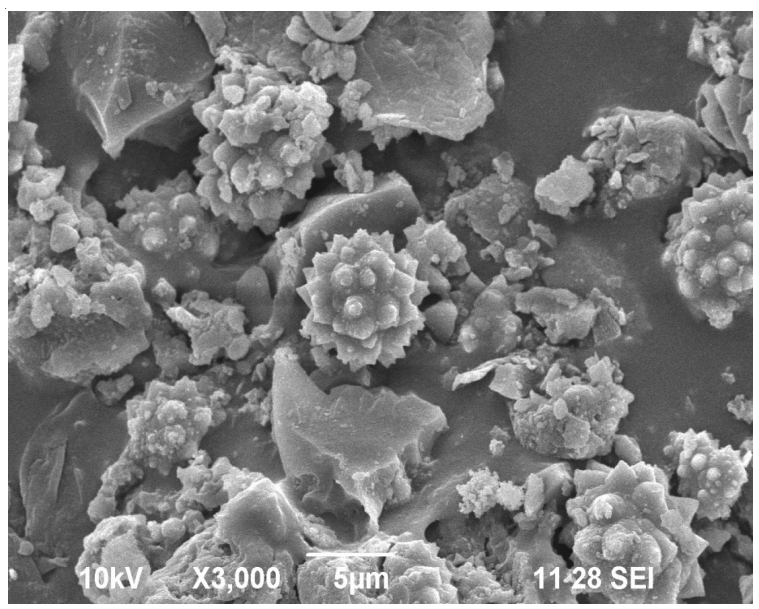

Fig. 5. SEM image of crystal violet loaded areca husk carbon

Effect of adsorbent dosage: The effect of adsorbent dosage on the removal of dye was studied by varying the dose of adsorbent from 50 to $250 \mathrm{mg}$ with the fixed dye concentration of $10 \mathrm{mg} \mathrm{L}^{-1}$ at $30{ }^{\circ} \mathrm{C}$ was shown in Fig. 6. The percentage of dye adsorbed increases as the adsorbent dose was increased. Above $100 \mathrm{mg}$ of adsorbent dose the equilibrium of dye were reached and the removal ratios of dyes held almost no vary, so the areca husk carbon of $100 \mathrm{mg}$ was chosen for subsequent experiment. Maximum adsorption of areca husk carbon occurs

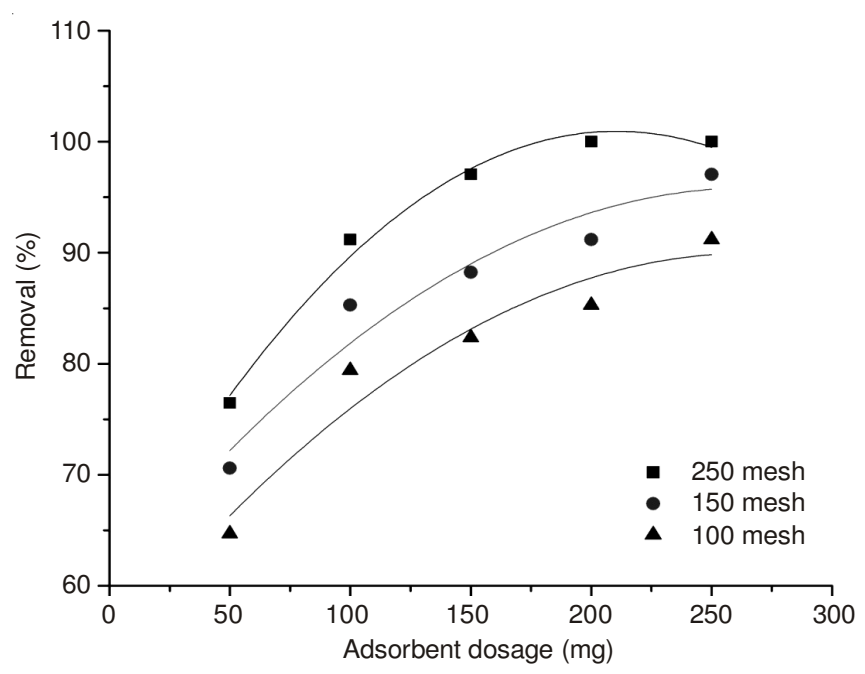

Fig. 6. Effect of adsorbent dosage on the removal of crystal violet dye onto areca husk carbon [dye concentration $=10 \mathrm{mg} \mathrm{L}^{-1}$; contact time $=2 \mathrm{~h}$; agitation speed $=120 \mathrm{rpm} ; \mathrm{T}=30^{\circ} \mathrm{C} ; \mathrm{pH} 7$; particle size $=100-250$ BSS mesh]

at particle size of $250 \mathrm{BSS}$ mesh adsorption decreases with increase in the size of adsorbent.

Effect of contact time: The effect of contact time on removal of dye was shown in Fig. 7. The studies involving different contact time help in determining the uptake capacities of the dye at varying time intervals by keeping the amount of adsorbent fixed. It was established that in the case of $100 \mathrm{mg}$ of areca husk carbon $2 \mathrm{~h}$ of contact time was found sufficient to acquire equilibrium. The adsorption rate was found to decrease with increase in time. To check the percentage removal of areca husk carbon were carried out at different particle size 100-250 BSS mesh the uptake of dye increased from 87 to 100 .

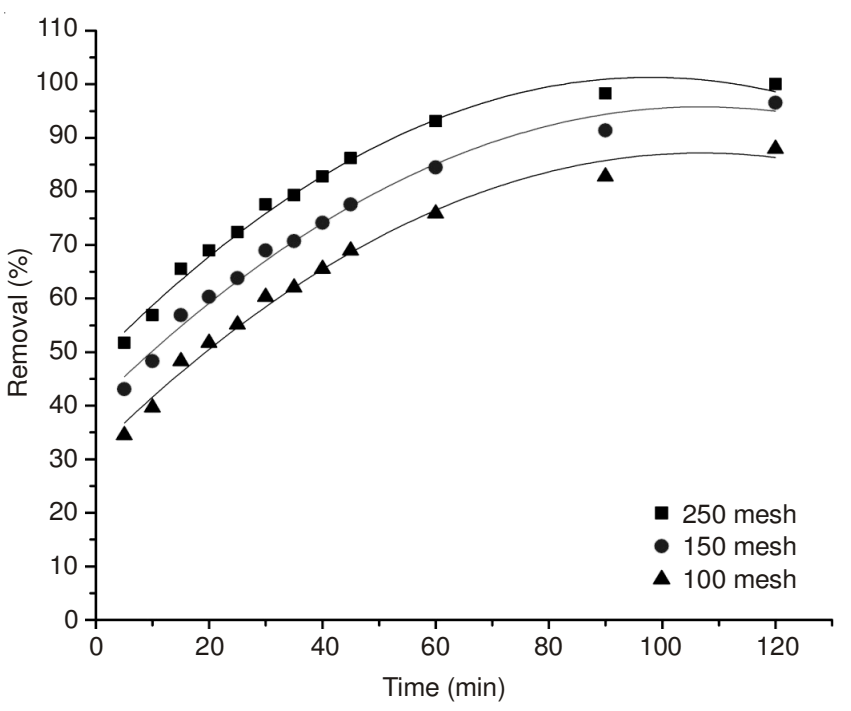

Fig. 7. Effect of contact time on the removal of crystal violet dye onto areca husk carbon [dye concentration $=10 \mathrm{mg} \mathrm{L}^{-1}$; contact time $=$ $2 \mathrm{~h}$; sorbent dosage $=100 \mathrm{mg} ;$ agitation speed $=120 \mathrm{rpm} ; \mathrm{T}=30$ ${ }^{\circ} \mathrm{C} ; \mathrm{pH} 7$; particle size $=100-250 \mathrm{BSS}$ mesh]

Effect of initial concentration and particle size: The effect of initial dye concentration was studied by varying the dye concentration from 5 to $20 \mathrm{mg} \mathrm{L}^{-1}$ at $30{ }^{\circ} \mathrm{C}$ shows rapid 
adsorption of dye in the first $15 \mathrm{~min}$. The adsorption of crystal violet from a solution of initial concentration $20 \mathrm{mg} \mathrm{L}^{-1}$ has been found to increase from 80 to $85 \%$ with a decrease in the particle size from 100-250 BSS mesh at room temperature. The study shows enhancement of crystal violet removal with decrease of particle size of the adsorbent attributed to the increase in the surface area is represented in the Figs. 8-10. The adsorption rate was decreased gradually and the adsorption reached equilibrium. It reveals that equilibrium was established for $2 \mathrm{~h}$ for all the concentration studied was shown in Figs. 8-10.

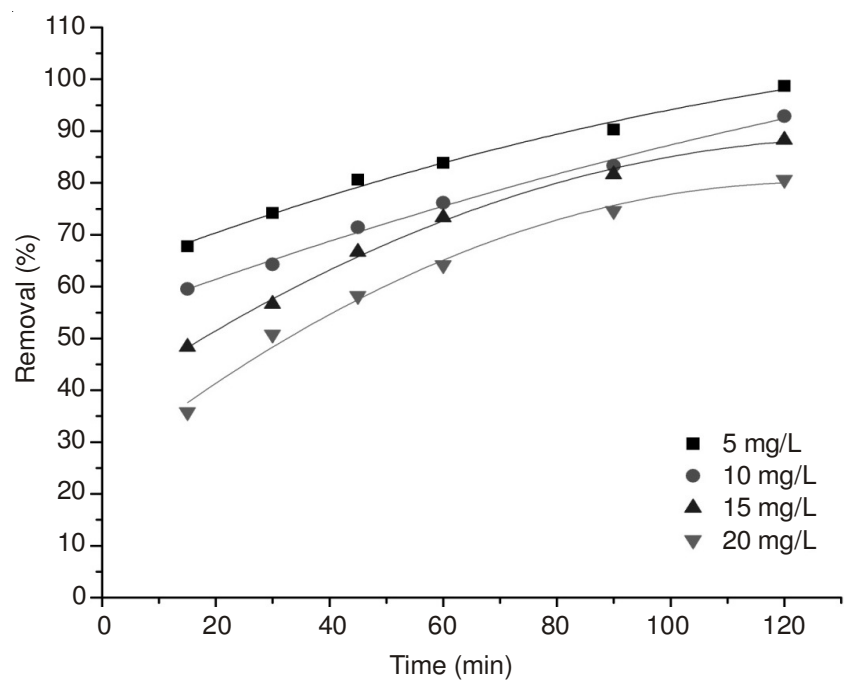

Fig. 8. Effect of initial dye concentration on the removal of crystal violet dye onto areca husk carbon [contact time $=2 \mathrm{~h}$; sorbent dose $=100$ $\mathrm{mg} ;$ agitation speed $=120 \mathrm{rpm} ; \mathrm{T}=30{ }^{\circ} \mathrm{C} ; \mathrm{pH} 7$; particle size $=100$ BSS mesh]

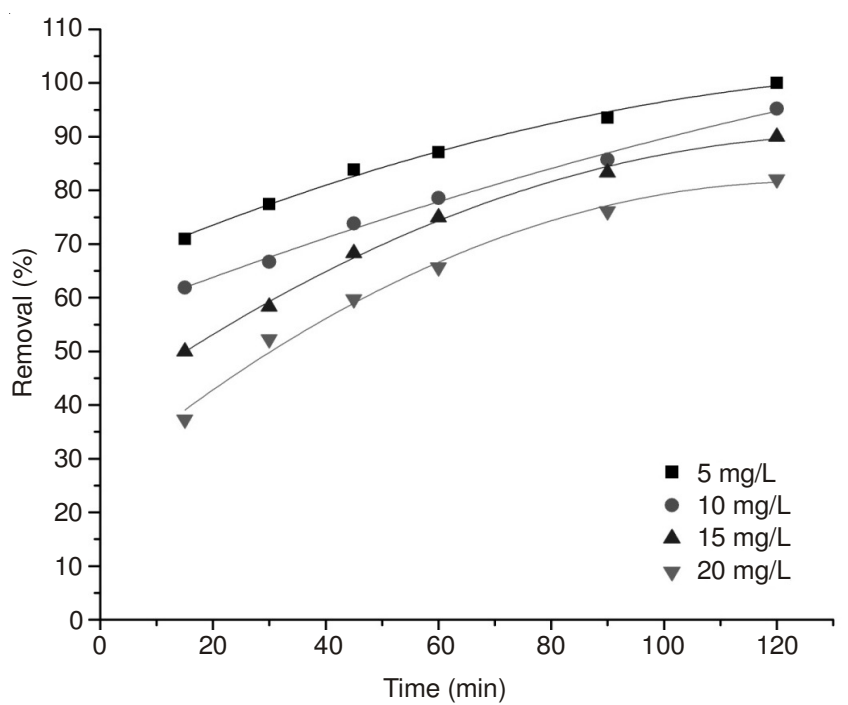

Fig. 9. Effect of Initial dye concentration on the removal of crystal violet dye onto areca husk carbon [contact time $=2 \mathrm{~h}$; sorbent dose $=100$ $\mathrm{mg}$; agitation speed $=120 \mathrm{rpm} ; \mathrm{T}=30^{\circ} \mathrm{C} ; \mathrm{pH} 7$; particle size $=150$ BSS mesh]

Effect of pH: To study the effect of pH on crystal violet adsorption on adsorbent, the experiment was carried out at $250 \mathrm{mg} \mathrm{L}^{-1}$ initial dye concentration with $10 \mathrm{mg} / 100 \mathrm{mg} \mathrm{L}^{-1}$ adsorbent mass for $2 \mathrm{~h}$ equilibrium time. The dye adsorption efficiency was not affected except minor variation in the $\mathrm{pH}$ range of 2-7 as shown in Fig. 11.

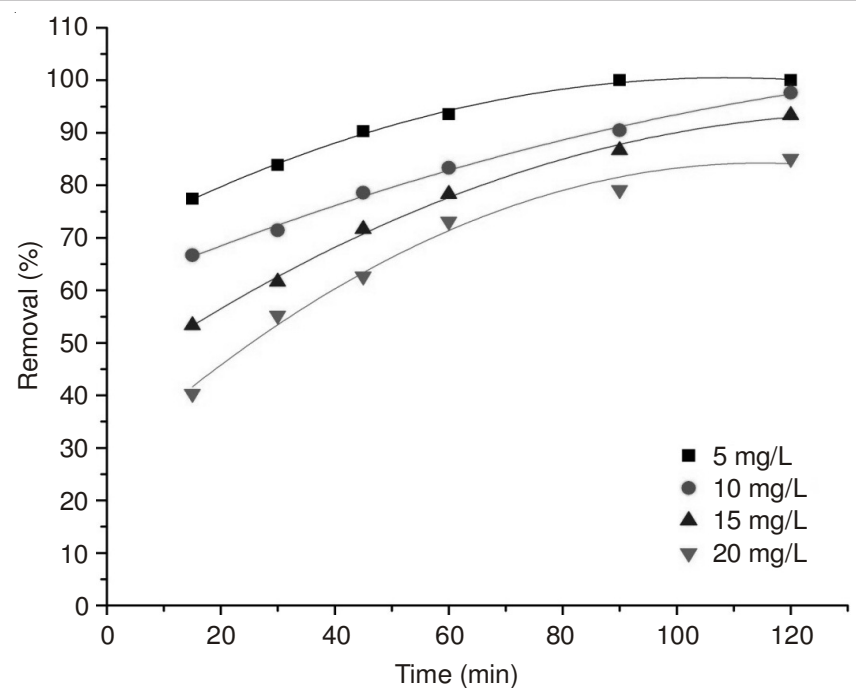

Fig. 10. Effect of initial dye concentration on the removal of crystal violet dye onto areca husk carbon [contact time $=2 \mathrm{~h}$; sorbent dose $=100$ mg; agitation speed $=120 \mathrm{rpm} ; \mathrm{T}=30^{\circ} \mathrm{C} ; \mathrm{pH} 7$; particle size $=250$ BSS mesh]

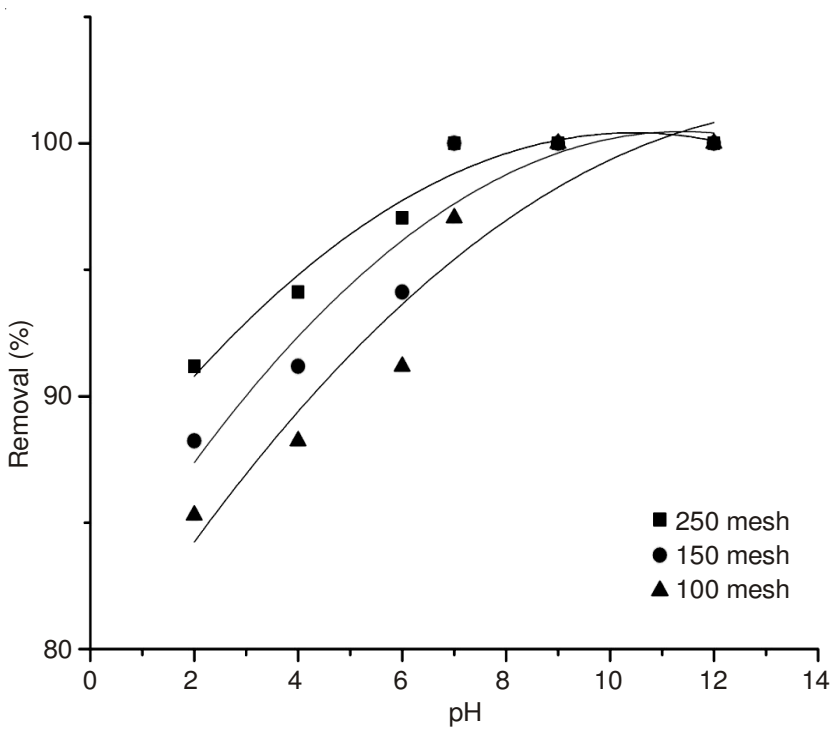

Fig. 11. Effect of $\mathrm{pH}$ on the removal of crystal violet dye onto areca husk carbon $\left[\right.$ dye concentration $=10 \mathrm{mg} \mathrm{L}^{-1}$; contact time $=2 \mathrm{~h}$; sorbent dose $=100 \mathrm{mg}$; agitation speed $=120 \mathrm{rpm} ; \mathrm{T}=30^{\circ} \mathrm{C}$; particle size $=250 \mathrm{BSS}$ mesh $]$

Adsorption kinetics: The study of adsorption kinetics describes the solute uptake rate and evidently these rate controls the residence time of adsorbate uptake at the solid-solution interface including the diffusion process. The kinetic study for the adsorption of crystal violet was conducted at optimum $\mathrm{pH}$ level 7, where maximum adsorption takes place. The adsorption study was tested for three models i.e. pseudo first order, pseudo second order and intra-particle diffusion model ${ }^{13}$. The experiments were carried out for time intervals varied from the 0 to $120 \mathrm{~min}$ at constant temperature, with 10 and 20 $\mathrm{mg} \mathrm{L}^{-1}$ of crystal violet by keeping other parameters constant.

Pseudo first order kinetic model: Lagergren proposed a pseudo-first order kinetic model as below ${ }^{14}$.

The integrated form of the model is:

$$
\log \left(\mathrm{q}_{\mathrm{e}}-\mathrm{q}_{\mathrm{t}}\right)=\log \mathrm{q}_{\mathrm{e}}-\frac{\mathrm{k}_{1}}{2} \cdot 303 \mathrm{t}
$$


where $\mathrm{k}_{1}\left(\mathrm{~min}^{-1}\right)$ is the rate constant of the pseudo-first order adsorption and $\mathrm{q}_{\mathrm{t}}$ is the adsorption capacity at time ' $\mathrm{t}$ ' $\left(\mathrm{mg} \mathrm{g}^{-1}\right)$. The rate parameters $\mathrm{k}_{1}$ and $\mathrm{q}_{\mathrm{e}}$ can be directly obtained from the intercept and slope of the plot of $\log \left(\mathrm{q}_{\mathrm{e}}-\mathrm{q}_{\mathrm{t}}\right) \mathrm{V}_{\mathrm{s}} \mathrm{t}$. The correlation values of $\mathrm{R}^{2}$ were 0.9826 to 0.9967 for particle size between 100-250 BSS mesh respectively .The equilibrium adsorption capacities were $8.79,9.66$ and $10 \mathrm{mg} \mathrm{g}^{-1}$ respectively. The calculated equilibrium adsorption capacities were $5.69,6.02$ and $6.34 \mathrm{mg} \mathrm{g}^{-1}$. The calculated and experimental results reveal that, the pseudo-first order model provided a better approximation to the experimental kinetic data than the pseudo-second order model for adsorption of crystal violet from aqueous solution. The rate constant and other results obtained graphically were presented in Table-1.

TABLE-1

KINETIC PARAMETERS FOR THE ADSORPTION OF CRYSTAL VIOLET DYE ONTO ARECA HUSK CARBON

\begin{tabular}{|c|c|c|c|}
\hline Kinetic model & \multicolumn{3}{|c|}{ Particle size } \\
\hline Pseudo-first order & 250 BSS mesh & 150 BSS mesh & $100 \mathrm{BSS}$ mesh \\
\hline $\mathrm{q}_{\mathrm{e}}\left(\mathrm{mg} \mathrm{g}^{-1}\right)$ & 10 & 9.66 & 8.79 \\
\hline $\mathrm{q}_{\text {calc }}\left(\mathrm{mg} \mathrm{g}^{-1}\right)$ & 6.34 & 6.02 & 5.69 \\
\hline $\mathrm{k}_{1}\left(\min ^{-1}\right)$ & 0.0168 & 0.0091 & 0.0274 \\
\hline $\mathrm{R}^{2}$ & 0.9826 & 0.9957 & 0.9967 \\
\hline \multicolumn{4}{|l|}{ Pseudo-second order } \\
\hline $\mathrm{q}_{\text {calc }}\left(\mathrm{mg} \mathrm{g}^{-1}\right)$ & 1.71 & 1.44 & 0.95 \\
\hline $\mathrm{k}_{2}\left(\mathrm{~g} \mathrm{mg}^{-1} \min ^{-1}\right)$ & 0.1023 & 0.0965 & 0.0927 \\
\hline $\mathrm{h}\left(\mathrm{mg} \mathrm{g}^{-1} \mathrm{~min}^{-1}\right)$ & 0.2990 & 0.2006 & 0.0838 \\
\hline $\mathrm{R}^{2}$ & 0.9964 & 0.9800 & 0.9800 \\
\hline \multicolumn{4}{|c|}{ Intra-particle diffusion } \\
\hline $\mathrm{k}_{\mathrm{int}}\left(\mathrm{mg} \mathrm{g}^{-1} \min ^{-0.5}\right)$ & 0.59 & 0.62 & 0.64 \\
\hline $\mathrm{C}$ & 4.26 & 3.05 & 2.32 \\
\hline $\mathrm{R}^{2}$ & 0.9443 & 0.9891 & 0.9730 \\
\hline
\end{tabular}

Pseudo-second-order kinetic model: The pseudosecond-order kinetic model is based on the assumption that the sorption follows second order chemisorptions. Pseudosecond-order kinetic model is given as:

$$
\frac{\mathrm{dq}}{\mathrm{dt}}=\mathrm{k}_{2}\left(\mathrm{q}_{\mathrm{e}}-\mathrm{q}_{\mathrm{t}}\right)^{2}
$$

After integrating we get

$$
\frac{\mathrm{t}}{\mathrm{q}_{\mathrm{t}}}=\frac{1}{\mathrm{k}_{2} \mathrm{q}_{\mathrm{e}}{ }^{2}}+\frac{\mathrm{t}}{\mathrm{q}_{\mathrm{e}}}
$$

where $\mathrm{k}_{2}\left[\mathrm{~g} \mathrm{mg}^{-1} \mathrm{~min}^{-1}\right]$ is the rate constant of the pseudosecond- order adsorption ${ }^{15}$ and $\mathrm{q}_{\mathrm{t}}$ is the adsorption capacity at time ' $\mathrm{t}$ ' $\left(\mathrm{mg} \mathrm{g}^{-1}\right)$.

The initial sorption rate $\mathrm{h}\left[\mathrm{mg} \mathrm{g}^{-1} \mathrm{~min}^{-1}\right]$ is defined as:

$$
\mathrm{h}=\mathrm{k}_{2} \mathrm{q}^{2}
$$

where $\mathrm{k}_{2}$ is the pseudo-second order rate constant of dye adsorption. The plot of $\mathrm{t} / \mathrm{q}$ versus $\mathrm{t}$ should give a linear relationship, from which $\mathrm{q}_{\mathrm{eq}}$ and $\mathrm{k}_{2}$ can be determined from the slope and intercept of the plot are listed in the Table- 1 the correlation values are close to the unity. The rate constant $\mathrm{k}_{2}$ were 0.0927 to $0.1023 \mathrm{~g} \mathrm{mg}^{-1} \mathrm{~min}^{-1}$ for particle size between $100-250 \mathrm{BSS}$ mesh respectively. In addition to the $\mathrm{q}_{\mathrm{e}}$ calculated values and the experimental values $\mathrm{q}_{\mathrm{e}}$ are not similar showing that the adsorption kinetics for the entire process did not follow the pseudo second order model. It can be concluded that the pseudo first order model provided a good correlation for the adsorption of crystal violet on areca husk carbon compared to the pseudo second order model.

Intra-particle diffusion model: There are essentially three consecutive mass transport steps associated with the adsorption of solute from the solution by an adsorbent. These are (i) film diffusion, (ii) intra-particle or pore diffusion and (iii) sorption into interior sites. The third step is very rapid and hence film and pore transports are the major steps controlling the rate of adsorption. In order to understand the diffusion mechanism, kinetic data was further analyzed using the intraparticle diffusion model based on the theory proposed by Weber and Morris.

The intra-particle diffusion equation is given as:

$$
\mathrm{q}_{\mathrm{t}}=\mathrm{K}_{\text {int }} \mathrm{t}^{0.5}+\mathrm{C}
$$

$\mathrm{k}_{\text {int }}$, the intra-particle diffusion rate constant are listed in Table-1. The plot of $\mathrm{q}_{\mathrm{t}} v s . \mathrm{t}^{0.5}$ using the initial kinetic data up to 120 min gave correlation coefficient $\left(\mathrm{R}^{2}\right)$ values of 0.9443 to 0.9891 for the areca husk carbon. The high $\mathrm{R}^{2}$ value indicates that intra-particle diffusion might play a significant role in the initial stage of the adsorption. The value of intercept give an idea about the thickness of boundary layer i.e., larger the intercept greater is the boundary layer ${ }^{16}$. The deviation of straight line from the origin may be due to the different in the rate of mass transfer in the initial and the final stage of adsorption as shown in the Fig. 12.

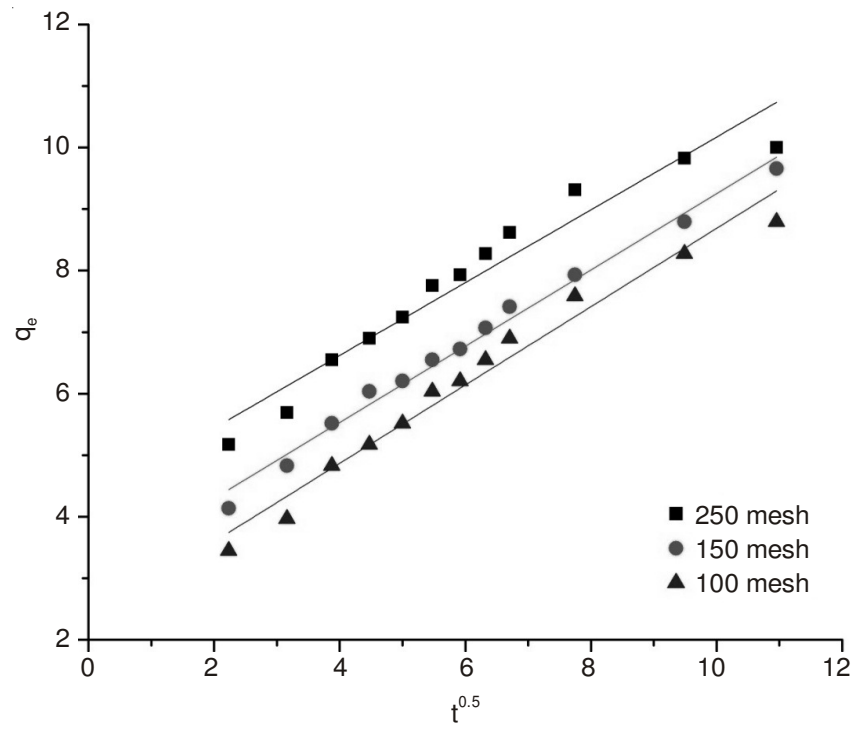

Fig. 12. Intra particle diffusion plots for the adsorption of crystal violet dye onto areca husk carbon

\section{Isotherm study}

Langmuir isotherm: Langmuir isotherm model is based on assumption that a saturated monolayer of adsorbate molecules is present on the adsorbent surface, the adsorption energy is constant and there is no migration of adsorbate molecules in the surface plane when maximum adsorption capacity occurs. The linear transformation of the Langmuir equation is given by

$$
\frac{1}{q_{e}}=\frac{1}{q_{0} b C_{e}}+\frac{1}{q_{0}}
$$


where $\mathrm{q}_{\mathrm{o}}$ is the maximum amount of adsorbate per unit mass of adsorbent form a complete monolayer on the surface ${ }^{17}, C_{e}$ denotes equilibrium adsorption concentration in solution, $\mathrm{q}_{\mathrm{e}}$ is the amount adsorbed per unit mass of adsorbent and $b$ is the binding energy constant. A plot of $1 / \mathrm{C}_{\mathrm{e}} v s .1 / \mathrm{q}_{\mathrm{e}}$ is graphically represented in Fig. 13. The values of $\mathrm{Q}_{0}$ and $\mathrm{b}$ were calculated from the intercept and slope respectively and the results are presented in Table-2. A further analysis of the Langmuir equation can be made on the basis of a dimensionless equilibrium parameter ${ }^{18}, \mathrm{R}_{\mathrm{L}}$ also known as the separation factor that is given by the following equation.

$$
\mathrm{R}_{\mathrm{L}}=\frac{1}{\left(1+\mathrm{bC}_{0}\right)}
$$

\begin{tabular}{|c|c|c|c|}
\hline \multicolumn{4}{|c|}{$\begin{array}{l}\text { TABLE-2 } \\
\text { OTHERM PARAMETERS FOR THE } \\
\text { OF CRYSTAL VIOLET DYE ONTO } \\
\text { ECA HUSK CARBON }\end{array}$} \\
\hline Isotherm model & \multicolumn{3}{|c|}{ Particle size } \\
\hline Langmuir Isotherm & $\begin{array}{c}250 \text { BSS } \\
\text { mesh }\end{array}$ & $\begin{array}{c}150 \text { BSS } \\
\text { mesh }\end{array}$ & $\begin{array}{c}100 \text { BSS } \\
\text { mesh }\end{array}$ \\
\hline $\mathrm{Q}_{0}\left(\mathrm{mg} \mathrm{g}^{-1}\right)$ & 76.9 & 72.2 & 69.8 \\
\hline $\mathrm{R}_{\mathrm{L}}$ & 3.48 & 3.10 & 2.50 \\
\hline $\mathrm{b}\left(\mathrm{L} \mathrm{mg}^{-1}\right)$ & 0.25 & 0.21 & 0.15 \\
\hline $\mathrm{R}^{2}$ & 0.9814 & 0.9601 & 0.9589 \\
\hline \multicolumn{4}{|l|}{ Freundlich isotherm } \\
\hline $\mathrm{k}_{\mathrm{f}}\left(\mathrm{mg} \mathrm{g}^{-1}\right)$ & 16.98 & 13.80 & 11.22 \\
\hline $\mathrm{n}$ & 2.02 & 1.91 & 1.87 \\
\hline $\mathrm{R}^{2}$ & 0.9989 & 0.9920 & 0.9906 \\
\hline \multicolumn{4}{|l|}{ Temkin Isotherm } \\
\hline A & 1.25 & 1.09 & 0.95 \\
\hline $\mathrm{b}$ & 46.27 & 47.08 & 45.41 \\
\hline B & 53.91 & 52.98 & 54.92 \\
\hline $\mathrm{R}^{2}$ & 0.9658 & 0.9197 & 0.9310 \\
\hline
\end{tabular}

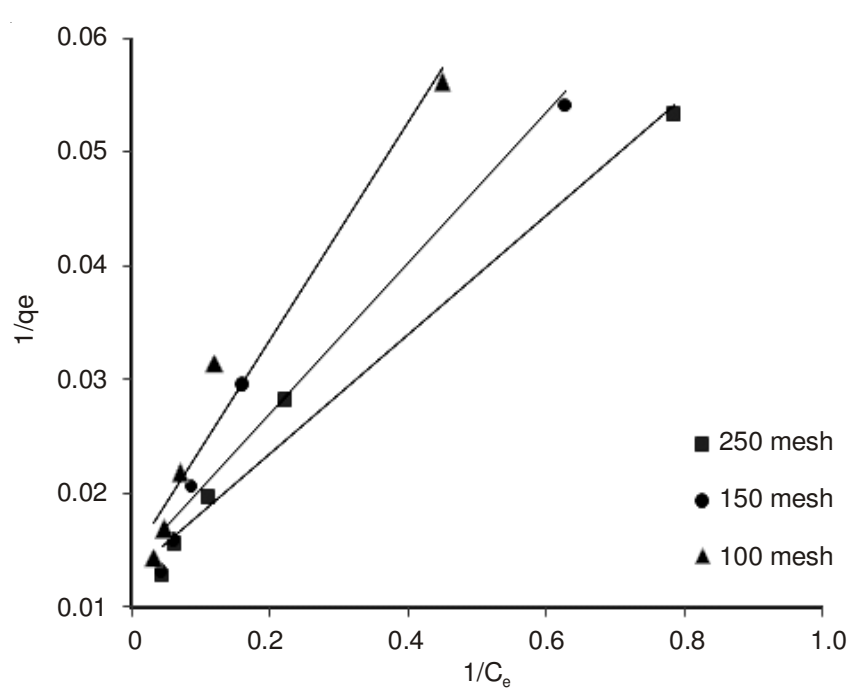

Fig. 13. Linearized Langmuir adsorption isotherm for the adsorption of crystal violet dye onto areca husk carbon

The data related to the equilibrium obeyed well with the Langmuir models. The maximum adsorption capacity of adsorption of crystal violet by Langmuir isotherm was 69.8 to $76.9 \mathrm{mg} \mathrm{g}^{-1}$. Q $\mathrm{Q}_{\mathrm{o}}$ value increases with increase in particle size between 100-250 BSS mesh. The $\mathrm{R}^{2}$ value 0.9589 to 0.9814 suggests that the Langmuir isotherm provides a good fit to the isotherm data The value of $R_{L}$ was 0.29 to 0.40 which indicates the favour of adsorption i.e. formation of monolayer of crystal violet on the surface of areca husk carbon.

Freundlich isotherm: Freundlich isotherm model is the empirical relationship that assumes heterogeneous adsorption due to the diversity of adsorption sites.

The Freundlich equation is expressed as:

$$
\ln \mathrm{q}_{\mathrm{e}}=\ln \mathrm{K}_{\mathrm{F}}+\frac{1}{\mathrm{n}} \ln \mathrm{C}_{\mathrm{e}}
$$

where $\mathrm{K}_{\mathrm{F}}$ is measure of adsorption capacity $\left(\mathrm{mg} \mathrm{g}^{-1}\right)$ and $\mathrm{n}$ is adsorption intensity. $1 / \mathrm{n}$ values indicate the type of isotherm to be irreversible $(1 / \mathrm{n}=0)$, favorable $(0<1 / \mathrm{n}<1)$, unfavorable $(1 / \mathrm{n}>1)$. The linear plot of $\ln \mathrm{q}_{\mathrm{e}} v s . \ln \mathrm{C}_{\mathrm{e}}$ was shown in Fig. 16. The values of $1 / \mathrm{n}$ and $\mathrm{k}_{\mathrm{f}}$ can be calculated from the slope and intercept respectively and the results are given in Table-2. From the experimental data the value of $1 / \mathrm{n}$ was less than one indicating the favorable adsorption. The $\mathrm{k}_{\mathrm{f}}$ is the measure of adsorption capacity and $\mathrm{n}$ is the adsorption intensity (favorability of adsorption) which is given in Table-2. The Freundlich adsorption capacity ${ }^{18}$ by this plot is 11.22 to 16.98 $\mathrm{mg} / \mathrm{g}$ and regression factor $\left(\mathrm{R}^{2}\right)$ were 0.9906 to 0.9989 , respectively (Fig. 14).

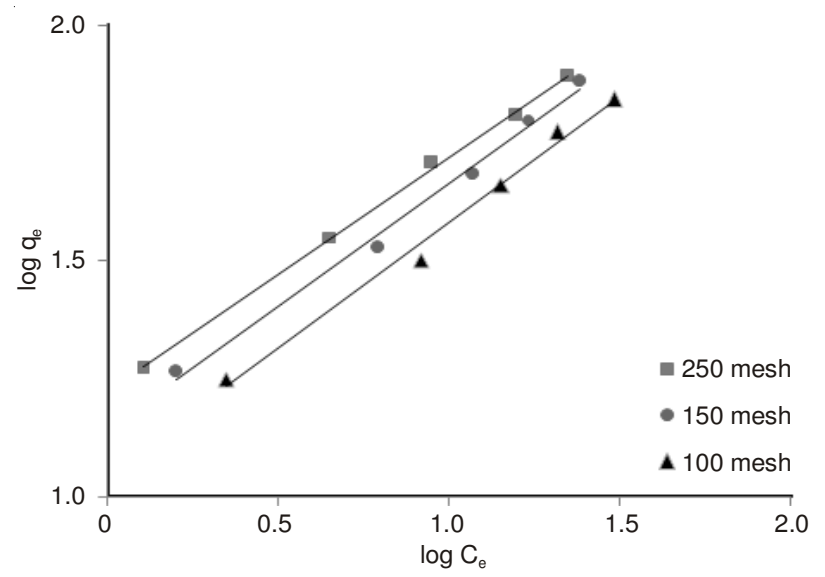

Fig. 14. Linearized Freundlich adsorption isotherm for the adsorption of crystal violet dye onto areca husk carbon

From the results it was clearly observed that both models were well suited for adsorption of crystal violet on areca husk carbon, but the regression factor as well as the calculated and experimental values correlates more correctly with the Langmuir values ${ }^{17}$, on this basis it could be concluded that crystal violet form monolayer on surface of areca husk carbon.

Temkin isotherm: Temkin isotherm model contains a parameter that explicitly accounts for the interaction of adsorbate and adsorbing species. It is based on the assumption that the heat of adsorption of all the molecules in the layer diminishes linearly with coverage which is attributed to adsorbateadsorbate repulsions. It also assumes that adsorption is due to uniform distribution of binding energy ${ }^{19}$. Contrary to Freundlich model, it assumes that fall in heat of adsorption is linear rather than logarithmic. The equation can be expressed as:

$$
\mathrm{q}_{\mathrm{e}}=\mathrm{B} \ln \mathrm{A}+\mathrm{B} \ln \mathrm{C}_{\mathrm{e}}
$$

where $\mathrm{B}=\mathrm{RT} / \mathrm{b}, \mathrm{b}$ is the Temkin constant related to heat of sorption $\mathrm{q}_{\mathrm{e}}\left(\mathrm{mg} \mathrm{g}^{-1}\right)$ and $\mathrm{C}_{\mathrm{e}}\left(\mathrm{mg} \mathrm{L}^{-1}\right)$ are the amount of adsorbed 
dye per unit weight of adsorbent and unabsorbed dye concentration in solution at equilibrium, respectively. Therefore, a plot of $\mathrm{q}_{\mathrm{e}} v s$. $\ln \mathrm{C}_{\mathrm{e}}$ enables one to determine the constants $\mathrm{A}$ and $\mathrm{B}$. The values of the Temkin constants $\mathrm{A}$ and $\mathrm{B}$ were determined from Fig. 15 and were found to be 0.95 to 1.25 and 45.41 to 47.08 , respectively. The correlation coefficient of 0.9197 to 0.9658 obtained showed that adsorption of crystal violet also followed the Temkin model.

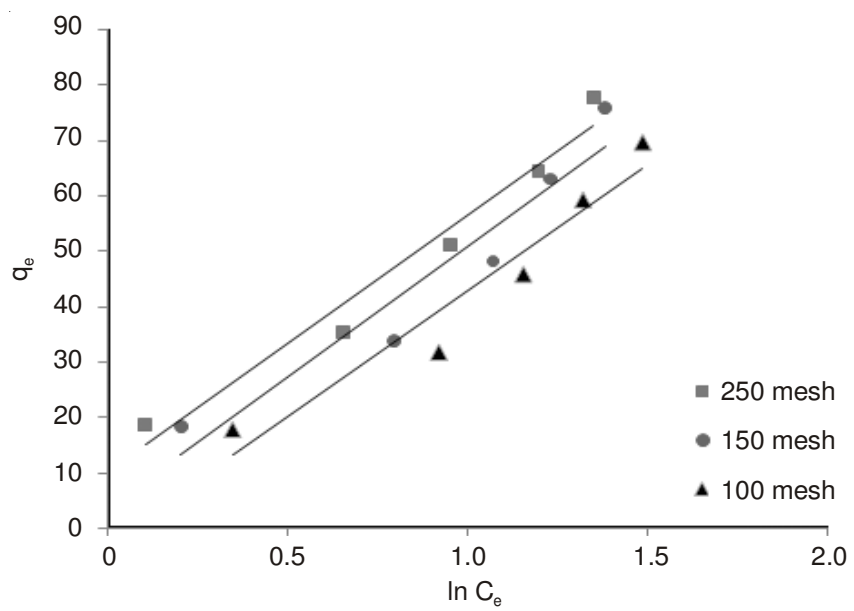

Fig. 15. Linearized Temkin adsorption isotherm for the adsorption of crystal violet dye onto areca husk carbon

Thermodynamic study: In order to investigate the effect of temperature on the uptake of crystal violet the process was carried out at different temperatures ranging from $300 \mathrm{~K}, 310$ $\mathrm{K}$ and $320 \mathrm{~K}$. The temperature affected the equilibrium uptake as shown in Fig. 16. The equilibrium crystal violet adsorption capacity of both the adsorbents were better at higher temperatures as the adsorbed amount of crystal violet increased with the rise in temperature. Higher uptake at high temperature is due to the increase in molecular diffusion or may be attributed to the availability of more active sites on the surface of the adsorbents by expansion of the pores. Temperature dependence of the adsorption process is related with several thermodynamic parameters including free energy change $\left(\Delta \mathrm{G}^{0}\right)$, enthalpy $\left(\Delta \mathrm{H}^{0}\right)$

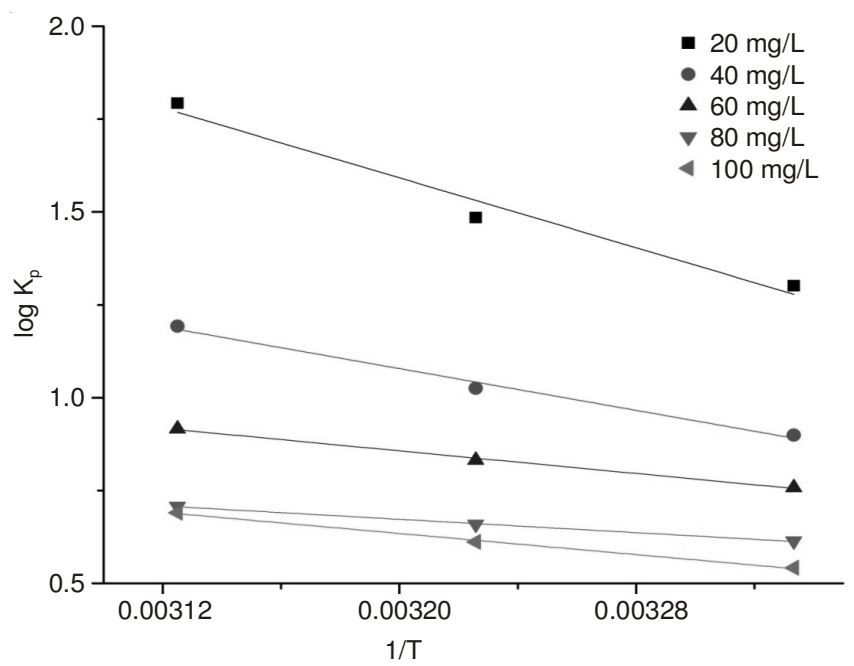

Fig. 16. vant-Hoff isotherm plot for the adsorption of crystal violet dye onto areca husk carbon and entropy $\left(\Delta S^{0}\right)$ which are used to decide whether the adsorption is a spontaneous process or not ${ }^{20}$. Thermodynamic parameters can be calculated from the following eqn.

$$
\Delta \mathrm{G}^{0}=-\mathrm{RT} \ln \mathrm{K}_{\mathrm{d}}
$$

where $\mathrm{R}$ is the universal gas constant $\left(8.314 \mathrm{~J} \mathrm{~mol}^{-1} \mathrm{~K}^{-1}\right)$, $\mathrm{T}$ the temperature $(\mathrm{K})$ and $\mathrm{K}_{\mathrm{d}}$ is the distribution coefficient. If the value of $\Delta \mathrm{G}^{\circ}$ is negative, the chemical reaction can occur spontaneously at a given temperature. The $\mathrm{K}_{\mathrm{d}}$ value was calculated using the following eqn. (13)

$$
\mathrm{k}_{\mathrm{d}}=\frac{\mathrm{C}_{\mathrm{e}}}{\mathrm{q}_{\mathrm{e}}}
$$

where $\mathrm{q}_{\mathrm{e}}$ and $\mathrm{C}_{\mathrm{e}}$ are the equilibrium concentrations of crystal violet $\left(\mathrm{mg} \mathrm{L}^{-1}\right)$ on the adsorbent and in the solution, respectively. The enthalpy change $\left(\Delta \mathrm{H}^{0}\right)$ and entropy change $\left(\Delta \mathrm{S}^{0}\right)^{21}$ can be calculated from the following equation.

$$
\Delta \mathrm{G}^{0}=\Delta \mathrm{H}^{0}-\mathrm{T} \Delta \mathrm{S}^{0}
$$

This equation can be written as

$$
\ln \mathrm{K}_{\mathrm{d}}=\frac{\Delta \mathrm{S}^{0}}{\mathrm{R}}-\frac{\Delta \mathrm{H}^{0}}{\mathrm{RT}}
$$

The thermodynamic parameters of $\Delta \mathrm{H}^{\circ}$ and $\Delta \mathrm{S}^{\circ}$ were obtained from the slope and intercept of the plot between log $\mathrm{K}_{\mathrm{d}}$ versus $1 / \mathrm{T}$ respectively from the Fig. 16 . The Gibbs free energy changes $\left(\Delta \mathrm{G}^{0}\right)$ were calculated from eqn. (12) and the values of $\Delta \mathrm{G}^{0}, \Delta \mathrm{H}^{0}$ and $\Delta \mathrm{S}^{0}$ for the adsorption of crystal violet onto areca husk carbon were given in Table-3. The negative values $^{22}$ of $\Delta G^{0}$ indicated the spontaneous nature of the adsorption process. The magnitude of $\Delta \mathrm{G}^{0}$ also increased with increasing temperature indicating that the adsorption was more favorable at higher temperatures. The value of $\Delta \mathrm{H}^{\mathrm{o}}$ was -ve, indicating the exothermic nature of the adsorption of crystal violet onto areca husk carbon. The adsorption of crystal violet onto areca husk carbon was a physical process because of the obtained $\Delta \mathrm{H}^{0}$ value was -47.5 to $-114.9 \mathrm{~kJ} \mathrm{~mol}^{-1}$. Hence the

\begin{tabular}{|c|c|c|c|c|c|}
\hline \multicolumn{6}{|c|}{$\begin{array}{c}\text { TABLE-3 } \\
\text { THERMODYNAMIC PARAMETERS FOR THE ADSORPTION OF } \\
\text { CRYSTAL VIOLET DYE ONTO ARECA HUSK CARBON }\end{array}$} \\
\hline Conc. & $\mathrm{T}(\mathrm{K})$ & $\mathrm{K}_{\mathrm{d}}$ & $\begin{array}{c}\Delta \mathrm{G}^{\circ} \\
\left(\mathrm{J} \mathrm{mol}^{-1}\right)\end{array}$ & $\begin{array}{c}\Delta \mathrm{S}^{\circ}(\mathrm{J} \\
\left.\mathrm{mol}^{-1} \mathrm{~K}^{-1}\right)\end{array}$ & $\begin{array}{c}\Delta \mathrm{H}^{\circ} \\
\left(\mathrm{kJ} \mathrm{mol}^{-1}\right)\end{array}$ \\
\hline \multirow{3}{*}{20} & 300 & 20.0 & $\begin{array}{l}-7472.0 \\
\end{array}$ & \multirow{3}{*}{358.098} & \multirow{3}{*}{-114.9} \\
\hline & 310 & 30.5 & -8524.5 & & \\
\hline & 320 & 62.0 & -10293.9 & & \\
\hline \multirow{3}{*}{40} & 300 & 7.9 & -5162.4 & \multirow{3}{*}{246.531} & \multirow{3}{*}{-79.1} \\
\hline & 310 & 10.6 & -5888.4 & & \\
\hline & 320 & 15.6 & -6847.7 & & \\
\hline \multirow{3}{*}{60} & 300 & 5.7 & -4353.0 & \multirow{3}{*}{206.175} & \multirow{3}{*}{-66.2} \\
\hline & 310 & 6.8 & -4777.4 & & \\
\hline & 320 & 8.3 & -5263.3 & & \\
\hline \multirow{3}{*}{80} & 300 & 4.1 & -3524.2 & \multirow{3}{*}{166.256} & \multirow{3}{*}{-53.4} \\
\hline & 310 & 4.6 & -3783.9 & & \\
\hline & 320 & 5.1 & -4062.1 & & \\
\hline \multirow{3}{*}{100} & 300 & 3.5 & -3110.3 & \multirow{3}{*}{147.986} & \multirow{3}{*}{-47.5} \\
\hline & 310 & 4.1 & -3513.7 & & \\
\hline & 320 & 4.9 & -3961.2 & & \\
\hline
\end{tabular}
adsorption equilibrium was rapidly attained and weak interactions between the crystal violet and the functional groups on the surface of the adsorbent. In addition, the positive value 
of $\Delta \mathrm{S}^{\circ}$ suggested an increase in randomness at the solid/liquid interface during the adsorption of crystal violet on the adsorbent.

Analysis of variance: The results of analysis of variance (ANOVA) are given in Tables 4-7. Statistical analysis of variance was performed to check whether the process parameters are statistically significant or not. The F-value for each process $^{23}$ indicates which parameter has a significant effect on the crystal violet removal. Since the probability value is bigger than 0.05 , the variances are not significantly different. Suppose the probability value is smaller than 0.05 , the variances are significantly different ${ }^{24}$. The larger the F-value has the greater the effect on the crystal violet removal. Optimal conditions for the process parameters can be predicted using

TABLE-4

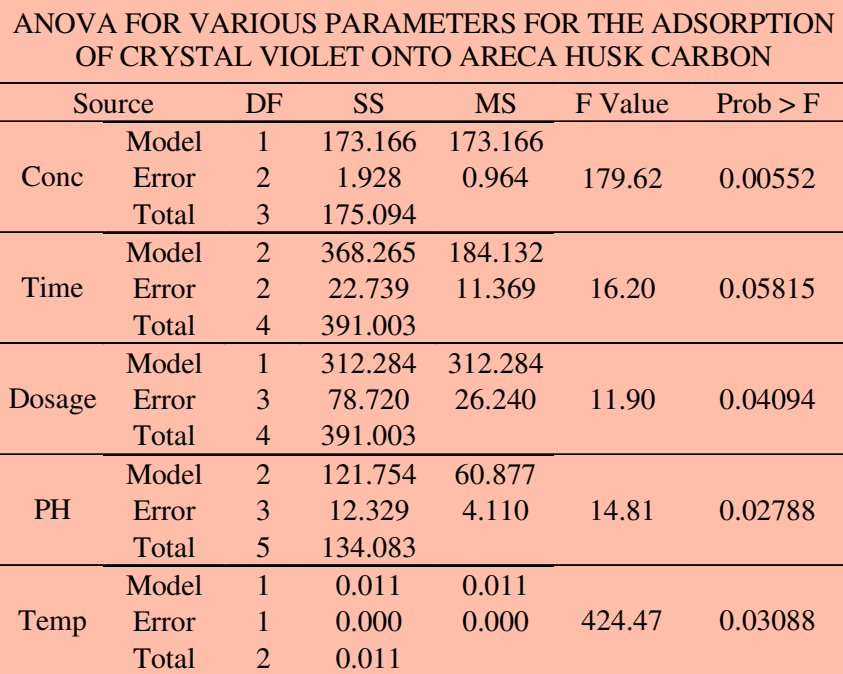

TABLE-5

ANOVA FOR KINETIC PARAMETERS FOR THE ADSORPTION OF CRYSTAL VIOLET ONTO ARECA HUSK CARBON

\begin{tabular}{ccccccc}
\hline \multicolumn{2}{c}{ Particle Size } & DF & SS & MS & F Value & Prob $>$ F \\
\hline \multirow{3}{*}{100 mesh } & Model & 1 & 0.29 & 0.29 & 534.18 & \\
& Error & 9 & 0.00 & 0.00 & & 0.000000003 \\
& Total & 10 & 0.29 & & & \\
\hline \multirow{3}{*}{150 mesh } & Model & 1 & 0.37 & 0.37 & 1452.60 & \\
& Error & 9 & 0.00 & 0.00 & & 0.00000000003 \\
& Total & 10 & 0.37 & & & \\
\hline \multirow{2}{*}{250 mesh } & Model & 1 & 1.69 & 1.69 & 486.10 & \\
& Error & 9 & 0.03 & 0.00 & & \\
& Total & 10 & 1.72 & & & 0.000000004 \\
\hline
\end{tabular}

\begin{tabular}{clccccc}
\multicolumn{7}{c}{ TABLE 6 } \\
\multicolumn{7}{c}{$\begin{array}{c}\text { ANOVA FOR ISOTHERM PARAMETERS FOR } \\
\text { THE ADSORPTION OF CRYSTAL VIOLET } \\
\text { ONTO ARECA HUSK CARBON }\end{array}$} \\
\hline \multicolumn{2}{c}{ Particle Size } & DF & SS & MS & F Value & Prob>F \\
\hline \multirow{3}{*}{100 mesh } & Model & 1 & 0.00106 & 0.00106 & 158.36 & 0.00108 \\
& Error & 3 & 0.00002 & 0.00001 & & \\
& Total & 4 & 0.00108 & & & \\
\hline \multirow{3}{*}{150 mesh } & Model & 1 & 0.00106 & 0.00106 & 72.18 & 0.00342 \\
& Error & 3 & 0.00004 & 0.00001 & & \\
& Total & 4 & 0.00111 & & & \\
\hline \multirow{3}{*}{250 mesh } & Model & 1 & 0.00111 & 0.00111 & 70.01 & 0.00358 \\
& Error & 3 & 0.00005 & 0.00002 & & \\
& Total & 4 & 0.00116 & & & \\
\hline
\end{tabular}

ANOVA analysis and performance characteristics. The results of ANOVA analysis for the removal of crystal violet onto areca husk carbon are given in Table-4. Larger the F-value more is the effective parameter in the crystal violet uptake. The sequential order of the process variables is given below for crystal violet removal onto areca husk carbon.

Time $>$ dosage $>$ temp $>\mathrm{pH}>\mathrm{C}_{\mathrm{o}}$

From the Tables 5 and 6 , kinetic and adsorption parameters shows at least two groups of the four have significant different means, since the p-value is smaller than 0.05 . Some of the pvalues are found to be bigger than 0.05 in the Thermodynamic ANOVA parameters as shown in Table- 7 we can conclude that the four groups have equal variance, since the $\mathrm{p}$-value is bigger than 0.05 .

\begin{tabular}{|c|c|c|c|c|c|c|}
\hline \multicolumn{7}{|c|}{$\begin{array}{c}\text { TABLE-7 } \\
\text { ANOVA FOR THERMODYNAMIC PARAMETERS } \\
\text { FOR THE ADSORPTION OF CRYSTAL VIOLET } \\
\text { ONTO ARECA HUSK CARBON }\end{array}$} \\
\hline \multicolumn{2}{|c|}{$\begin{array}{c}\text { Adsorbate } \\
\text { concentration }\end{array}$} & DF & SS & MS & F Value & Prob $>F$ \\
\hline \multirow{3}{*}{$20 \mathrm{mg} / \mathrm{L}$} & Model & 1 & 0.120020 & 0.120020 & 36.40 & 0.10456 \\
\hline & Error & 1 & 0.003300 & 0.003300 & & \\
\hline & Total & 2 & 0.123310 & & & \\
\hline \multirow{3}{*}{$40 \mathrm{mg} / \mathrm{L}$} & Model & 1 & 0.042910 & 0.042910 & 102.70 & 0.06262 \\
\hline & Error & 1 & 0.000418 & 0.000418 & & \\
\hline & Total & 2 & 0.043330 & & & \\
\hline \multirow{3}{*}{$60 \mathrm{mg} / \mathrm{L}$} & Model & 1 & 0.012540 & 0.012540 & 299.86 & 0.03672 \\
\hline & Error & 1 & 0.000042 & 0.000042 & & \\
\hline & Total & 2 & 0.012580 & & & \\
\hline \multirow{3}{*}{$80 \mathrm{mg} / \mathrm{L}$} & Model & 1 & 0.004380 & 0.004380 & 672.51 & 0.02454 \\
\hline & Error & 1 & 0.000007 & 0.000007 & & \\
\hline & Total & 2 & 0.004390 & & & \\
\hline \multirow{3}{*}{$100 \mathrm{mg} / \mathrm{L}$} & Model & 1 & 0.010960 & 0.010960 & 424.47 & 0.03088 \\
\hline & Error & 1 & 0.000026 & 0.000026 & & \\
\hline & Total & 2 & 0.010980 & & & \\
\hline
\end{tabular}

\section{Conclusion}

The present study focuses on the adsorption of crystal violet dye from aqueous solution using activated carbon derived from areca husk carbon. The adsorption capacity of the adsorbent was considerably affected by initial concentration, particle size, contact time, temperature, initial $\mathrm{pH}$ and adsorbent dose. The maximum uptake of crystal violet took place at a $\mathrm{pH}$ range of 7-14. The adsorption of crystal violet onto AHC was found to increase with increase in adsorbent dose. Based on correlation coefficient $\left(\mathrm{R}^{2}\right.$ value), the experimental data was best fitted for Langmuir model than Freundlich and Temkin isotherm models. The monolayer adsorption capacity of crystal violet The monolayer adsorption capacity of AHC for CV was found to be $76.9 \mathrm{mg} \mathrm{g}^{-1}$. The suitability of pseudo-first order, pseudo-second order and intra-particle diffusion kinetic models for the sorption of crystal violet onto areca husk carbon was also discussed. Kinetic data follows the pseudo-first order kinetic model. Intra-particle diffusion model proves that pore diffusion plays major in the dye adsorption. The calculated thermodynamic parameter shows the spontaneous and exothermic nature of the adsorption process. ANOVA indicated that the most considerable factor was time and adsorbent dosage. The results showed the possibility of areca husk carbon for dye removal from aqueous solution as an alternative for most costly used adsorbent (Table-8). 


\begin{tabular}{lcc}
\hline \multicolumn{3}{c}{ TABLE-8 } \\
\multicolumn{3}{c}{ ADSORPTION CAPACITY OF VARIOUS } \\
\multicolumn{1}{c}{ ADSORBENTS WITH CRYSTAL VIOLET } \\
\hline \multicolumn{1}{c}{ Adsorbent } & $\mathrm{Q}_{0}(\mathrm{mg} / \mathrm{g})$ & Reference \\
\hline Areca husk treated with $\mathrm{H}_{2} \mathrm{SO}_{4}$ & 76.9 & This study \\
Sewage sludge & 68.13 & {$[25]$} \\
Coconut husk & 61.60 & {$[25]$} \\
PAAC & 60.74 & {$[6]$} \\
Palygorskite & 57.93 & {$[26]$} \\
Waste apricot & 57.80 & {$[27]$} \\
UNCAL BC & 48.95 & {$[28]$} \\
Kaolin & 47.27 & {$[29]$} \\
Raw kaolin & 44.87 & {$[29]$} \\
CAL BC & 40.49 & {$[28]$} \\
Semi-IPN hydrogels & 35.09 & {$[30]$} \\
Jute fibre carbon & 27.99 & {$[31]$} \\
Bagasse fly ash & 26.23 & {$[32]$} \\
Wood apple rind & 16.5 & {$[33]$} \\
Unexpanded perlite & 3.30 & {$[34]$} \\
Expanded perlite & 1.14 & {$[34]$} \\
\hline
\end{tabular}

\section{ACKNOWLEDGEMENTS}

The authors are grateful to Kumaraguru college of Technology for doing the research by providing some of the equipments for the research.

\section{REFERENCES}

1. R. Ahmad, J. Hazard. Mater., 171, 767 (2009).

2. M. Asghar and H.N. Bhatti, Ecol. Eng., 38, 79 (2012).

3. H.N. Bhatti, N. Akhtar and N. Saleem, Arab. J. Sci. Eng., 37, 9 (2012).

4. Y. Safa and H.N. Bhatti, Afr. J. Biotechnol., 10, 3128 (2011).

5. S. Chakraborty, S. Chowdhury and P. Das Saha, Carbohydr. Polym., 86, 1533 (2011).

6. S. Senthilkumaar, P. Kalaamani and C. Subburaam, J. Hazard. Mater., 136, 800 (2006).

7. L.M. Hung, W.K. Yang and C.D. Hwang, Sep. Sci. Technol., 39, 1563 (2004)
8. C. Namasivayam and K. Kadirvelu, Bioresour. Technol., 62, 123 (1997).

9. D. Pravin Nemade, A.M. Kadam and H.S. Shankar, J. Environ. Biol., 30, 499 (2009).

10. S.P. Raghuvanshi, R. Singh, C.P. Kaushik, A.K. Raghav and A. Chandra, WAPDEC., 1053 (2002).

11. N. Deo and M. Ali, Indian J. Environ. Protect., 13, 496 (1993).

12. P. Monash and G. Pugazhenthi, Adsorption, 15, 390 (2009).

13. C. Namasivayam, R. Radhika and S. Suba, Waste Manage., 21, 381 (2001).

14. A. Bhatnagar and A.K. Jain, J. Colloid Interf. Sci., 281, 49 (2005).

15. R. Gündogan, B. Acemioglu and M.H. Alma, J. Colloid Interf. Sci., 269, 303 (2004).

16. G. McKay, M.S. Otterburn and A.G. Sweeny, Water Res., 14, 15 (1980).

17. R. Srivastava and D.C. Rupainwar, Indian J. Chem. Technol., 18, 67 (2011).

18. S.L. Hii, S.Y. Yong and C.L. Wong, J. Appl. Phycol., 21, 625 (2009).

19. G.O. El-Sayed, Desalination, 272, 225 (2011).

20. C. Namasivayam and D. Sangeetha, Bio. Res. Technol., 97, 1194 (2006).

21. P.V. Messina and P.C. Schulz, J. Colloid Interf. Sci., 299, 305 (2006).

22. E. Eren and B. Afsin, Dyes Pigments, 76, 220 (2008).

23. M.M.D. Zulkali, A.L. Ahmad and N.H. Norulakmal, Bioresour. Technol., 97, 21 (2006).

24. K. Ravikumar, S. Ramalingam, S. Krishnan and K. Balu, Dyes Pigments, 70, 18 (2006).

25. N. Graham, X.G. Chen and S. Jayaseelan, Water Sci. Technol., 43, 245 (2001).

26. A. Al-Futaisi, A. Jamrah and R. Al-Hanai, Desalination, 214, 327 (2007).

27. B. Ozkaya, A. Demir and M. Bilgili, J. Hazard. Mater., 135, 32 (2006).

28. P. Monash, R. Niwas and G. Pugazhenthi, Clean Technol. Environ. Policy, 13, 141 (2011).

29. B.K. Nandi, A. Goswami, A.K. Das, B. Mondal and M.K. Purkait, Sep. Sci. Technol., 43, 1382 (2008).

30. H. Li, G. Sheng, B.J. Teppen, C.T. Johnston and S.A. Boyd, Soil Sci. Soc. Am. J., 67, 122 (2003).

31. K. Porkodi and K. Vasanthkumar, J. Hazard. Mater., 143, 311 (2007).

32. I.D. Mall, V.C. Srivastava and N.K. Agarwal, Dyes Pigments, 69, 210 (2006).

33. R. Malarvizhi and Y.S. Ho, Desalination, 264, 97 (2010).

34. M. Dogan and M. Alkan, J. Colloid Interf. Sci., 267, 32 (2003). 